\title{
Infilled masonry walls contribution in mitigating progressive collapse of multistory reinforced concrete structures according to UFC guidelines
}

\author{
Huda Helmy ${ }^{1} \cdot$ Hamed Hadhoud $^{2} \cdot$ Sherif Mourad $^{2}$
}

Received: 3 November 2014/ Accepted: 7 June 2015/Published online: 27 June 2015

(c) The Author(s) 2015. This article is published with open access at Springerlink.com

\begin{abstract}
A structure is subjected to progressive collapse when an element fails, resulting in failure of adjoining structural elements which, in their turn, cause further structural failure leading eventually to partial or total collapse. The failure of a primary vertical support might occur due to extreme loadings such as bomb explosion in a terrorist attack, gas explosion and huge impact of a car in the parking area. Different guidelines such as the General Services Administration (GSA 2003) and the Unified Facilities Criteria (UFC 2009) addressed the structural progressive collapse due to the sudden loss of a main vertical support. In the current study, a progressive collapse assessment according to the UFC guidelines is carried out for a typical ten-story reinforced concrete framed structure designed according to codes [(ACI 318-08) and (ASCE 7-10)] for minimum design loads for buildings and other structures. Fully nonlinear dynamic analysis for the structure was carried out using Applied Element Method (AEM). The investigated cases included the removal of a corner column, an edge column, an edge shear wall, internal columns and internal shear wall. The numerical analysis showed that simplification of the problem into 3D bare frames would lead to uneconomical design. It was found for the studied case that, the infilled masonry walls have a valuable contribution in mitigating progressive collapse of the reinforced concrete framed structures. Neglecting these walls would lead to uneconomical design.
\end{abstract}

Huda Helmy

dr_hudahelmy@yahoo.com

Applied Science Int., Cairo, Egypt

2 Department of Structural Engineering, Cairo University, Giza, Egypt
Keywords Progressive collapse - UFC · ELS - AEM . Infilled walls · Catenary action - Collapsed area and rotation limits

\section{Introduction}

Several structural, progressive collapses took place worldwide in the last decades. For example, in 1968, the collapse of Ronan Building in East London took place due to a gas explosion on the 18th floor. In 1995, the Murrah Federal Office Building in Oklahoma City collapsed due to a terrorist bomb explosion on the ground floor. In 2001, the famous World Trade Center, New York, collapsed due to planes impacting on the towers' upper levels primary, vertical structural (Shankar 2004). The status of reinforced concrete structures regarding their vulnerability to progressive collapse has become an important question. Guidelines for designing buildings against progressive collapse have been recently developed such as the General Service Administration (GSA) (General Service Administration 2003) guidelines and the Unified Facilities Criteria (UFC) guidelines (Unified Facilities Criteria 2009). Those guidelines describe two main methods: direct one (Alternative Path Method) and indirect one (Tie Method). For the APM, guidelines allow neglecting slab contribution and rely only on framing actions of beams and columns. Moreover, the contribution of nonstructural infilled walls is not considered. The contribution of the infilled walls and its effect during different load cases was studied in different researches. Hao et al. (2002) found that that the infilled masonry affects not only the damage level but also the damage pattern of the frames. They showed that the empirical damage criterion for surface structures on an underground explosion site is rather conservative for 
modern reinforced concrete structures, but it appears to be reasonable for the masonry infilled in the frame. (Razzaghi and Javidnia 2015) found that infilled walls play a vital role in seismic performance of RC structures. (Tsai and Huang 2013) found that the influence of the partially infilled walls differs from each type. They may increase the collapse resistance of the building frame under column loss but with decreased ductile capacity. From the structural aspect, with a constant opening rate of $60 \%$, the wing-type wall is a better option than the parapet- and panel-type walls. The panel-type wall appears to be the worst choice since shear failure of their connected beam members may be induced.

The authors have investigated the effect of slabs in an earlier study using the applied element method (Helmy et al. 2012) and found out that the slabs' contribution cannot be ignored; otherwise, this will lead to uneconomical design. In the current study, the role of infilled walls is investigated. The analysis is carried out two times, once using 3D skeletal frame excluding slabs and walls and the second one using 3D frame including nonstructural infilled walls. In the current study, a progressive collapse assessment of a typical ten-story reinforced concrete structure was carried out according to the UFC guidelines. The structure was designed according to ACI 318-08 (ACI 2008) and ASCE 7-10 (ASCE 2010) guidelines. Fully nonlinear dynamic analysis for the structure due to removal of a primary vertical element is carried out using the Applied Element Method (AEM). AEM is based on discrete crack approach and is capable of following the structure's behavior to its total collapse (Galal and El-Sawy 2010; Sasani and Sagiroglu 2008; Salem et al. 2011; Park et al. 2009; Helmy et al. 2009; Sasani 2008; Wibowo et al. 2009; Tagel-Din and Rahman 2004; Salem 2011).

\section{Objective}

The objective of this study is to evaluate the contribution of the nonstructural infilled walls in prevention of the progressive collapse of multistory reinforced concrete structures designed according to the ACI 318-08 guidelines and subjected to a loss of primary vertical support. The regulation and guidance of the UFC guidelines are adopted for the analysis.

\section{UFC guidelines}

UFC guidelines (UFC 2009) define two design approaches. The first one is the direct design approach, which includes the Alternative Path method (AP) and the Specific Local Resistance (SLR), while the other one is the indirect design approach, which is called the Tie Force method (TF). In the
AP method, the structure should be capable of bridging over missing structural elements. The TF approach enhances continuity, ductility, and structural redundancy by requiring "ties" to keep the structure together in the event of an abnormal loading. In this study, only AP method is of main concern.

According to UFC code, the load combination depends on the analysis type, static or dynamic. In the current study, the analysis type is dynamic. For the dynamic analysis, the gravity load for the entire structure will be $[(0.9$ or 1.2DL) + (0.5LL or 0.2S)] (UFC 2009; ASCE/SEI 2005). Lateral loads must be taken into consideration with a value of $[0.002 \times($ sum of the gravity loads $(\mathrm{DL}+\mathrm{LL}))]$. For each removal case, four analyses must be carried out. In each analysis the lateral load will be applied in one of the main directions, i.e., east to west, west to east, north to south and south to north. The analysis specified by UFC assumes a sudden removal of a primary support like columns or walls. The removed column or wall has different locations depending on the structural system as shown in Fig. 1. In case of a wall having " $C$ " shape, either the flange or the web will be removed. The removal does not impede into the connection or the horizontal elements that attached to the column at the floor level. This is to reserve the continuity in the horizontal members. AP analyses is carried out for parking story, story with public area, first story, story directly below the roof, story at mid height and story above the location of a column splice or change in column size. For each analysis, the rotations of each of the beam, column and joint must be checked. The beam rotation is checked using Table (4-1) in the UFC, while the column and joint rotation is check using Tables (6-8) and (6-9) in the ASCE 41 (ASCE 41 2006).

\section{Applied element method (AEM)}

Literature has shown that the Applied Element Method (AEM) theory gives good estimations for large displacements and deformations of structures undergoing collapse



Fig. 1 Locations of removed supports according to UFC guidelines 
(Galal and El-Sawy 2010; Meguro and Tagel-Din (2000, 2001); Sasani and Sagiroglu 2008; Salem et al. 2011; Park et al. 2009; Helmy et al. 2009; Sasani 2008; Wibowo et al. 2009; Tagel-Din and Rahman 2004; Tagel-Din and Meguro 2000a, b; Salem 2011). AEM is a modeling method adopting the concept of discrete cracking. As shown in Fig. 2a, the structure in the AEM is modeled as an assembly of elements connected together along their surfaces through a set of normal and shear springs. The two elements shown in Fig. $2 \mathrm{~b}$ are assumed to be connected by normal and shear springs located at the contact points, which are distributed on the element faces. These connecting springs represent the state of stresses, strains and connectivity between elements. They can represent both concrete and steel reinforcing bars.

Each single element has $6 d f$ : three for translations and three for rotations. Relative translational or rotational displacement between two neighboring elements cause stresses in the springs located at their common face as shown in Fig. 3. Two neighboring elements can be totally separated once the springs connecting them rupture. Fully nonlinear path-dependant constitutive models are adopted in the AEM as shown in Fig. 4. For concrete in compression, an elasto-plastic and fracture model is adopted (Maekawa and Okamura 1983) as shown in Fig. 4a. When concrete is subjected to tension, a linear stress strain relation ship is adopted until cracking of the concrete springs, where the stresses then drop to zero. The residual stresses are then redistributed in the next loading step by applying the redistributed force values in the reverse direction. For concrete springs, the relationship between shear stress and shear strain is assumed to remain linear till the cracking of concrete. Then, the shear stresses drop down as shown in Fig. 4b. The level of drop of shear stresses depends on the aggregate interlock and friction at the crack surface.
For reinforcement springs, the model presented by Ristic et al. (Ristic et al. 1986) is used as shown in Fig. 4c. The stiffness of reinforcement is calculated based on the strain from the reinforcement spring, loading status (either loading or unloading) and the previous history of steel spring which controls the Bauschinger effect. The main advantage of this model is that it can consider easily the effects of partial unloading and Bauschinger effect without any additional complications to the analysis. The rupture strain of reinforcement is defined in ELS. For steel springs, the relationship between shear stress and shear strain is assumed to remain linearly and elastic as shown in Fig. 4d.

The solution for the dynamic problem adopts implicit step-by-step integration (Newmark-beta) method (Bathe 1982; Chopra 1995). The equilibrium equations represent a linear system of equations for each step. The solution of the equilibrium equations is commonly solved using Cholesky upper-lower decomposition. Once elements are separated, the stiffness matrix becomes singular. However, the stability of the overall system of equilibrium equations is kept because of the existence of the mass matrix. Separated elements may collide with other elements. In that case, new springs are generated at the contact points of the collided elements. The bricks are simulated as built in reality, in a staggered pattern and connected by mortar as shown in Fig. 5.

\section{Applied element modeling of masonry}

The anisotropy of material with brick units and mortar joints is considered in analysis as shown in Fig. 5. In spring level, springs that lie within one unit of brick are termed as 'Unit springs'. For those springs, the corresponding domain material is brick as isotropic nature and they are assigned to

Fig. 2 Modeling of a structure with AEM

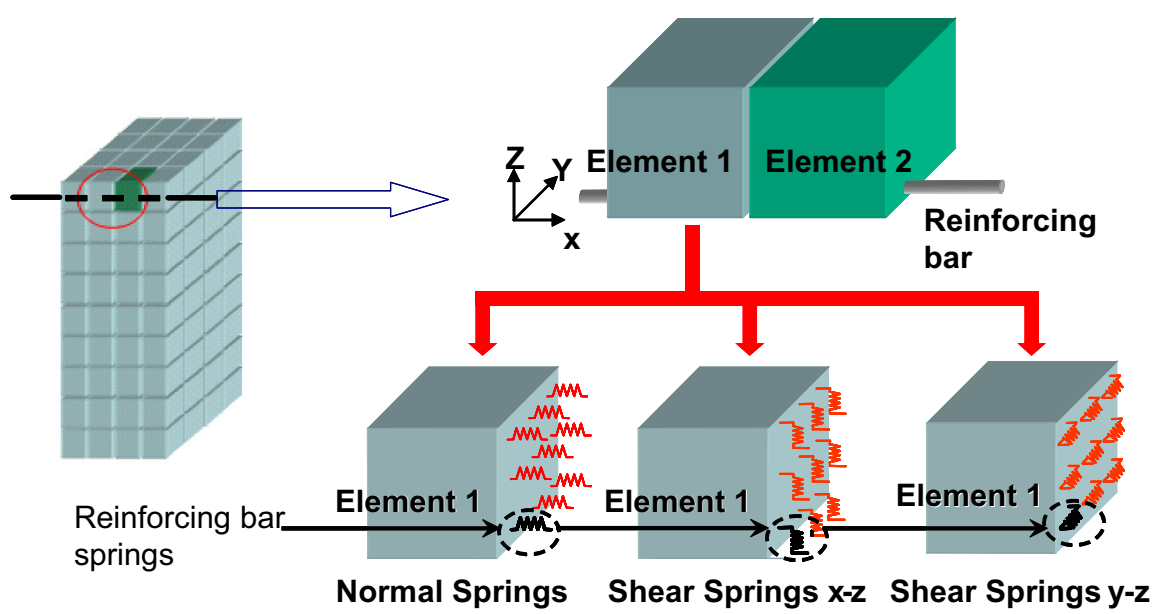

(a) Elements Discretization in AEM (b) Interface Springs between Adjacent Elements 
Fig. 3 Stresses in springs due to elements' relative displacement

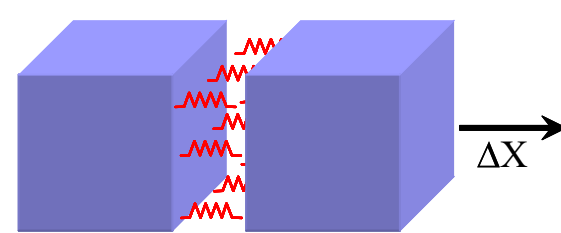

Normal Stresses
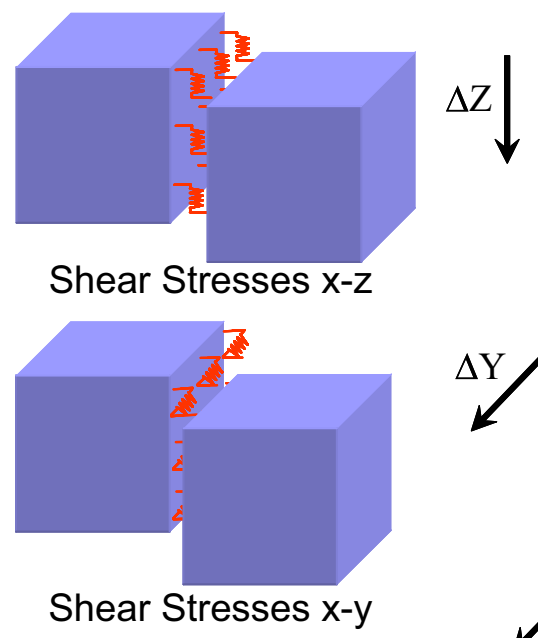

Relative Translations

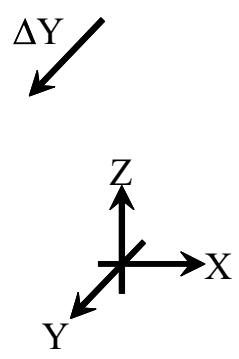

$\theta Z$

Normal Stresses
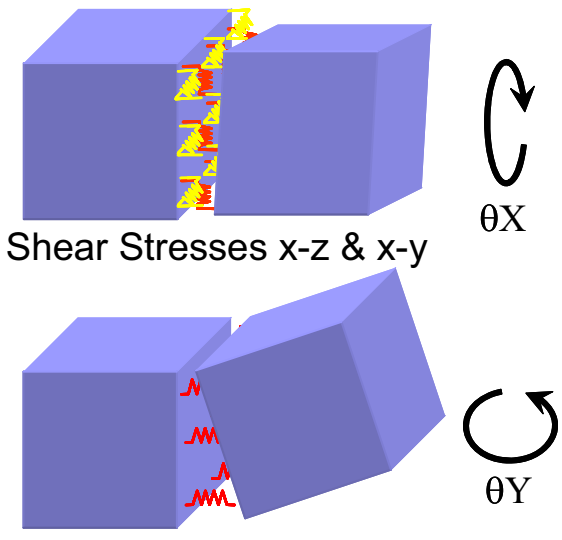

Normal Stresses

Relative Rotations structural properties of brick. Springs those accommodate mortar joints are treated as 'Joint springs'. They are defined by equivalent properties based on respective portion of unit and mortar thickness. Figure 5 shows the configuration of brick units, joints and their representation in this study. The initial elastic stiffness values of joint springs are defined as in Eqs. 1 and 2.

$$
\begin{aligned}
K_{\text {numit }} & =\left(E_{\mathrm{u}} \cdot t \cdot d / a\right) ; K_{\text {njoint }} \\
& =E_{\mathrm{u}} \cdot E_{\mathrm{m}} \cdot t \cdot d /\left[E_{\mathrm{u}} \cdot T_{\mathrm{h}}+E_{\mathrm{m}}\left(a-t_{\mathrm{h}}\right)\right] \\
G_{\text {sumit }} & =\left(G_{\mathrm{u}} \cdot t \cdot d / a\right) ; K_{\text {sjoint }} \\
& =G_{\mathrm{u}} \cdot G_{\mathrm{m}} \cdot t \cdot d /\left[G_{\mathrm{u}} \cdot T_{\mathrm{h}}+G_{\mathrm{m}}\left(a-t_{\mathrm{h}}\right)\right]
\end{aligned}
$$

where $E_{\mathrm{u}}$ and $E_{\mathrm{m}}$ are Young's modulus for brick unit and mortar, respectively, whereas $G_{\mathrm{u}}$ and $G_{\mathrm{m}}$ are shear modulus for the same. Thickness of wall is denoted by $t$ and $t_{\mathrm{h}}$ is mortar thickness. Dimension of element size is represented by $a$ and $d$ is the fraction part of element size that each spring represent.

Due to the fact that the mortar joint is weaker than the brick itself, it is expected that the crack will go through the mortar joint rather than the brick itself. Therefore, and due to the huge size of the full-scale case study, the brick element was decided not to be divided, i.e., to be considered as one element. Consequently, the joint stiffness calculated from Eq. 1 and Eq. 2 becomes very close to those of brick.

\section{Analytical model}

\section{Structure details}

The investigated structure is a ten-story reinforced concrete frame structure. All floors are typical, having an area of $1764 \mathrm{~m}^{2}$. The structure consists of seven equal bays in each direction; each bay is $6 \mathrm{~m}$ long. The ground floor is a public area (uncontrolled area) with a height of $4 \mathrm{~m}$ while all the other floors are $3 \mathrm{~m}$ high. A reinforced concrete core is used at the center of the structure at the elevators and staircase locations. Two shear walls are also placed at two edges of the structure as shown in Fig. 6. The structure was designed according to the building code requirements for structural concrete and commentary (ACI 318-08) (ACI 2008). Both gravity loads and lateral loads were considered in the structural design. All the loads' combinations were taken from (ASCE 7-2010) (ASCE 2010) guidelines. A three-dimensional detailed model was built using ELS (Applied Science International 2004-2015) software. ELS is AEM-based software, in which, all the structural details and reinforcement configuration are taken into consideration for the model as shown in Fig. 7. Figure 8 shows an isometric view for the ELS model. 


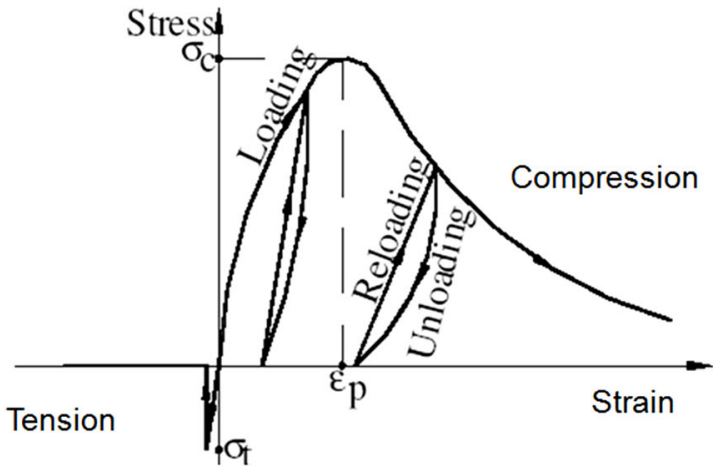

(a) Concrete under axial stresses



(c) Reinforcement under axial stresses

Fig. 4 Constitutive models for concrete and reinforcing bars

\section{Material properties}

Table 1 shows the concrete and reinforcement properties adopted in the analysis.

\section{Analytical approach}

According to UFC specifications and for a typical structure with an uncontrolled area in the ground floor, the analyses cases will be as follows:

1. Removal of a corner column.

2. Removal of an edge column.

3. Removal of an internal column.

4. Removal of another internal column near to the structure edge.

5. Removal of edge shear wall.

6. Removal of internal shear wall.

Removal of the main support from the ground floor was the only investigated case in the current research. One support is removed in each analysis. The column removal is applied suddenly at time $=0.00 \mathrm{~s}$. Figure 9 shows the

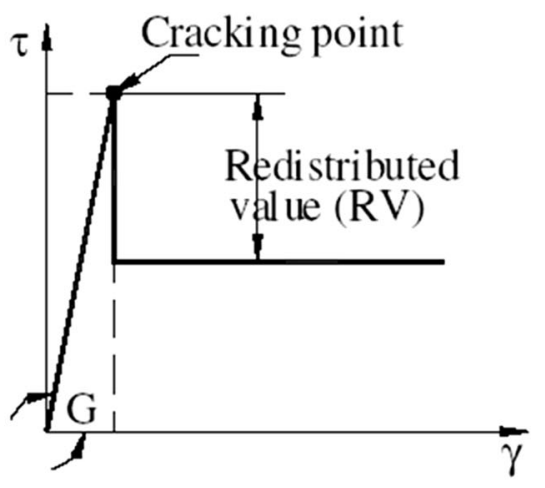

(b) Concrete under shear stresses

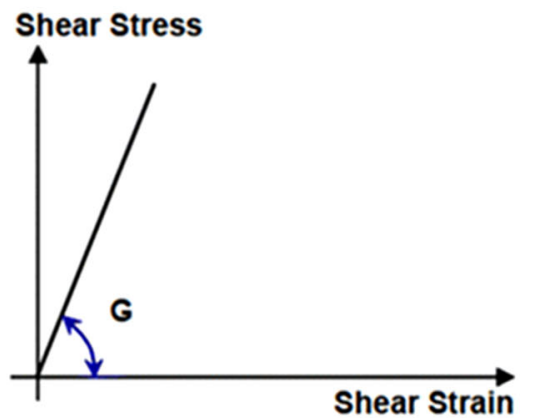

(d) Reinforcement under shear stress locations of removed supports. According to UFC, the adopted loading combination is $(1.2 \mathrm{DL}+0.50 \mathrm{LL})$ because all the analysis cases are nonlinear dynamic ones. The effect of the lateral load was considered in all the cases. The lateral load value is $0.002 \times$ (sum of the gravity loads "Dead and live"). The UFC code requires that for each analysis case, four separate analyses must be performed considering the lateral load (one analysis for each principal direction of the building). The analysis is carried out two times, once using 3D skeletal frame excluding slabs and walls and the third one using 3D frame including nonstructural infilled walls. The model consists of 41,300 elements on an average with 2,596,900 springs. The analysis time step is 0.001 . The analysis takes around $8 \mathrm{~h}$ to be finished.

Different patterns for the wall were considered in the analysis as shown in Fig. 10. For the edge wall cases, the window size and aspect ratio were investigated. For the interior wall cases, the minimum required number of walls was studied for different wall patterns. The results are compared to the GSA limits (collapsed area in case of collapse and beam rotation in case of no collapse). 
Fig. 5 Nonstructural masonry walls modeling
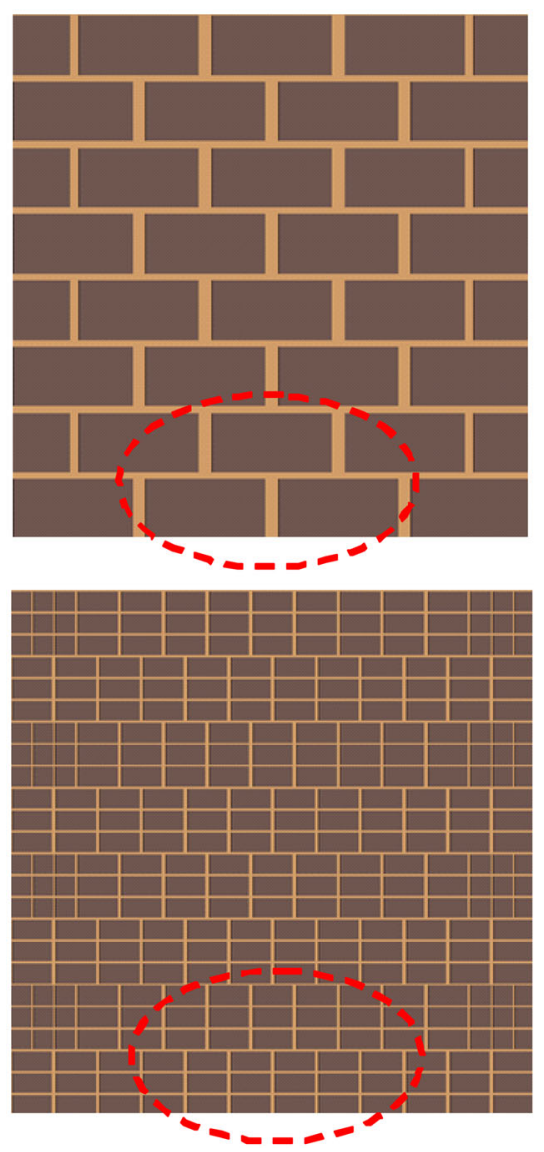
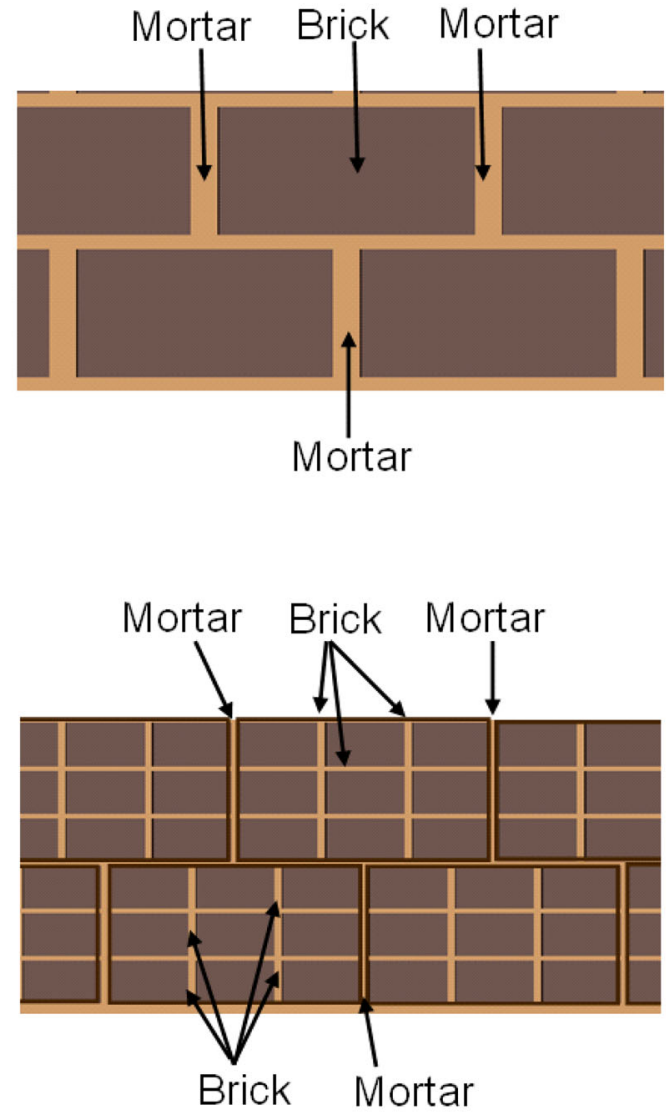

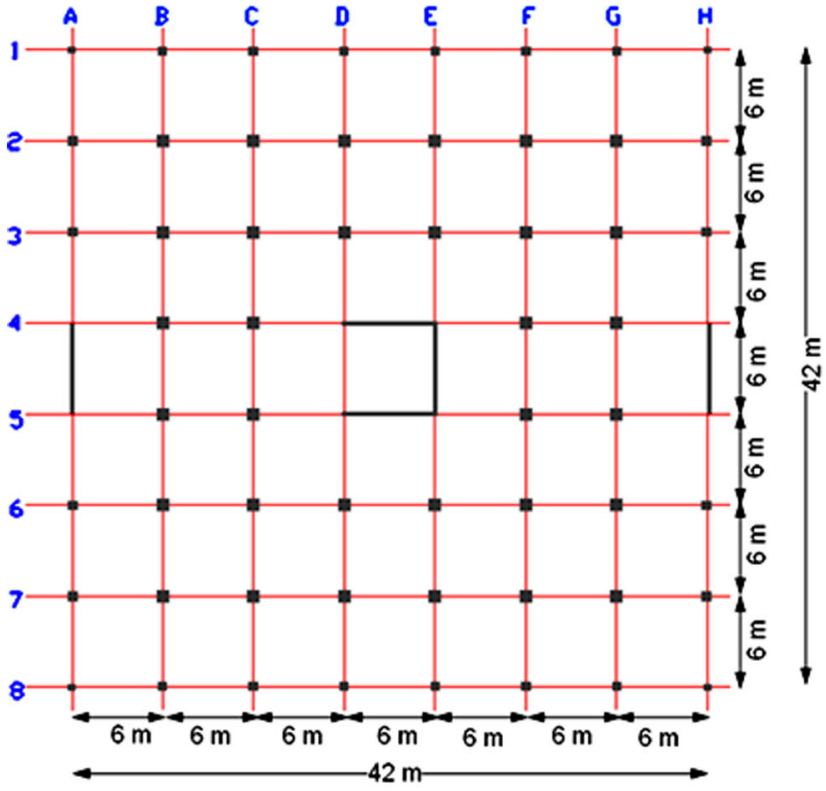

Plane view

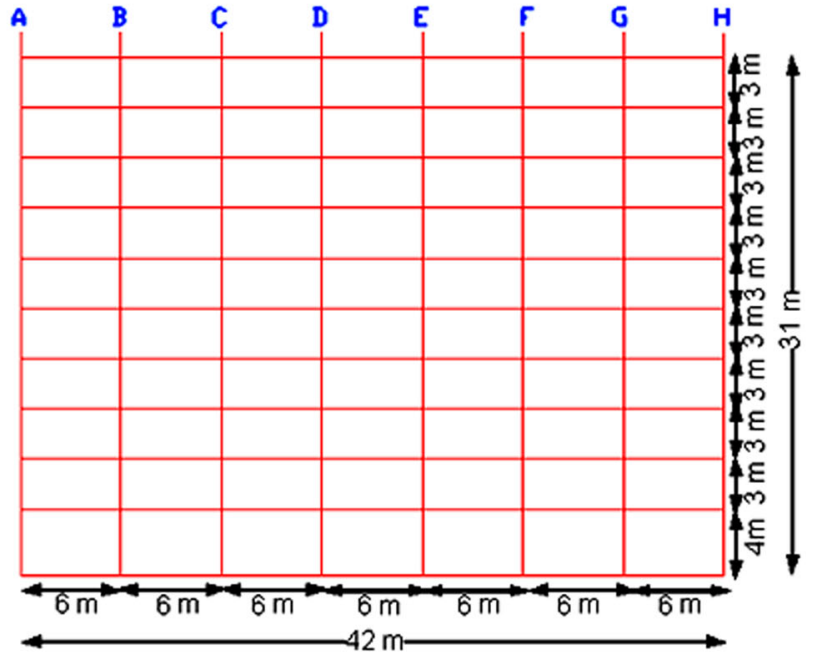

Elevation view

Fig. 6 Structure's general dimensions 
Fig. 7 Geometry and reinforcement details of the structure's components

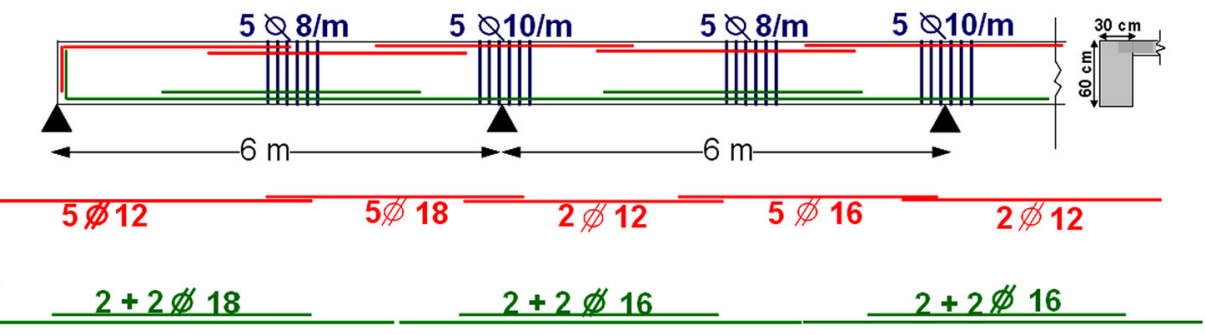

(a) Edge beam reinforcement

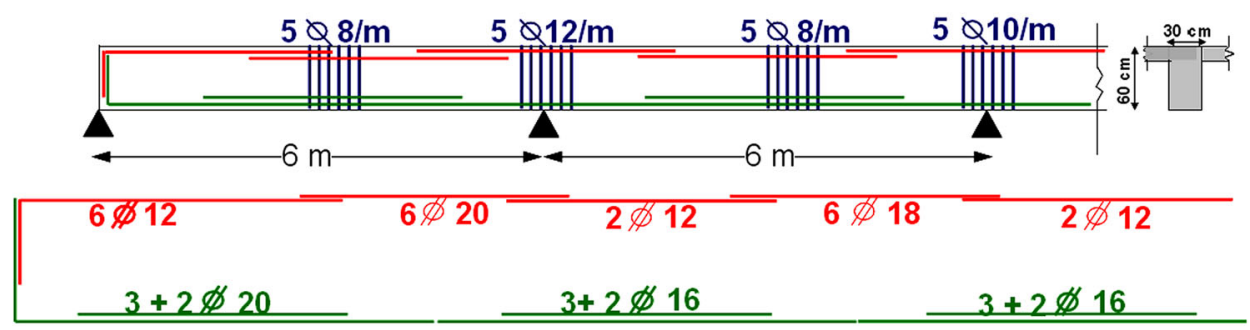

(b) Interior beam reinforcement

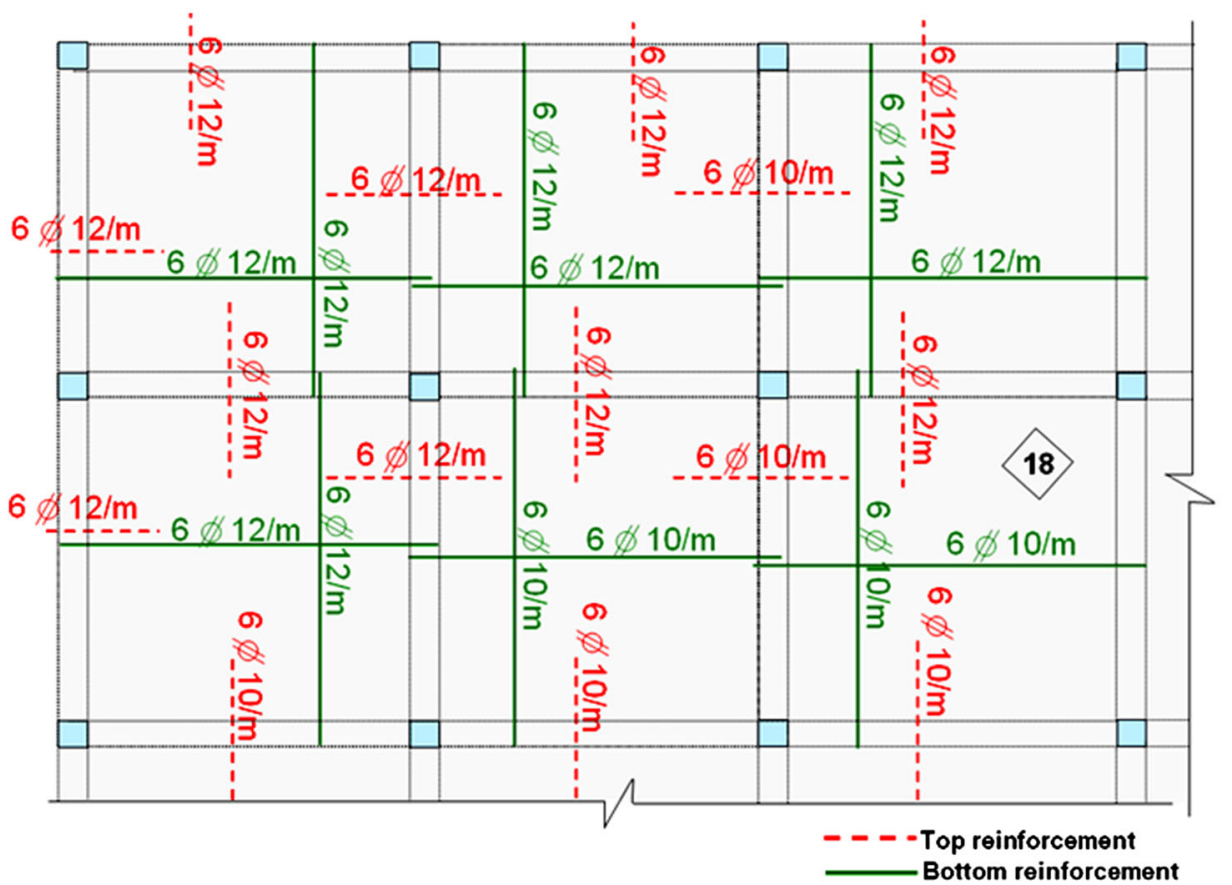

(c) Part plan showing typical slab reinforcement

\section{Analysis results and discussion}

\section{Mesh sensitivity}

A mesh sensitivity study was carried out for the case of edge column removal using four different mesh sizes. Different mesh discretizations are shown in Table 2. Figure 11 shows the relation between the mesh category and the deflection for an element just above the removed column. The change in the deflection from mesh \#3 to \#4 was found to be negligible enough. Consequently, the third mesh was chosen to be used in the analysis in the current study.

\section{Rotation of structural components}

According to the UFC code, the rotations of all the beams, columns and joints due to support loss must be checked. The beam and column rotation is calculated by dividing the maximum deflection of the member by the member length as shown in Fig. 12. The joint rotation is the relative rotations of the connected members. 
Fig. 7 continued

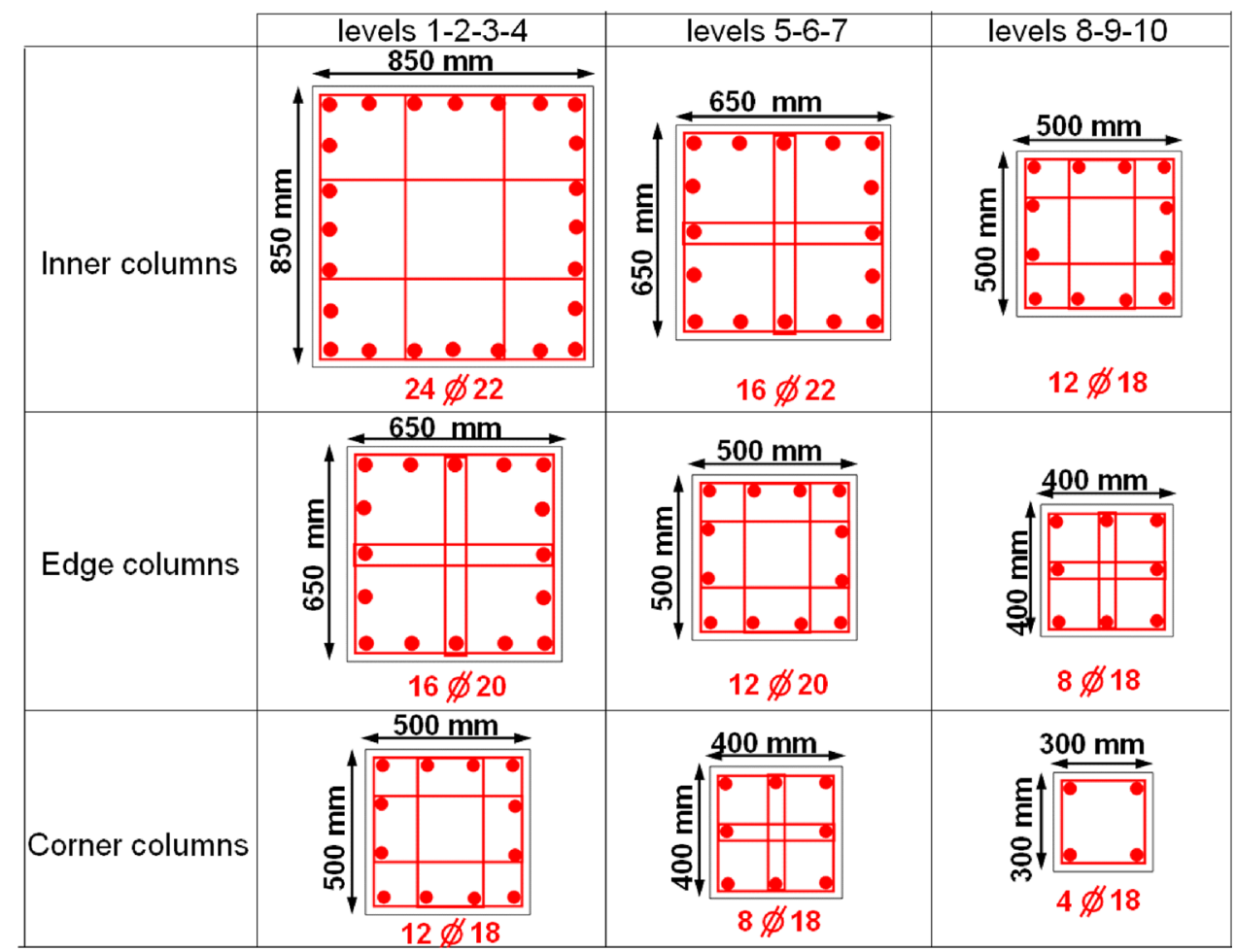

All stirrups are $5 \varnothing 10 / \mathrm{m}$

(d) Columns reinforcement

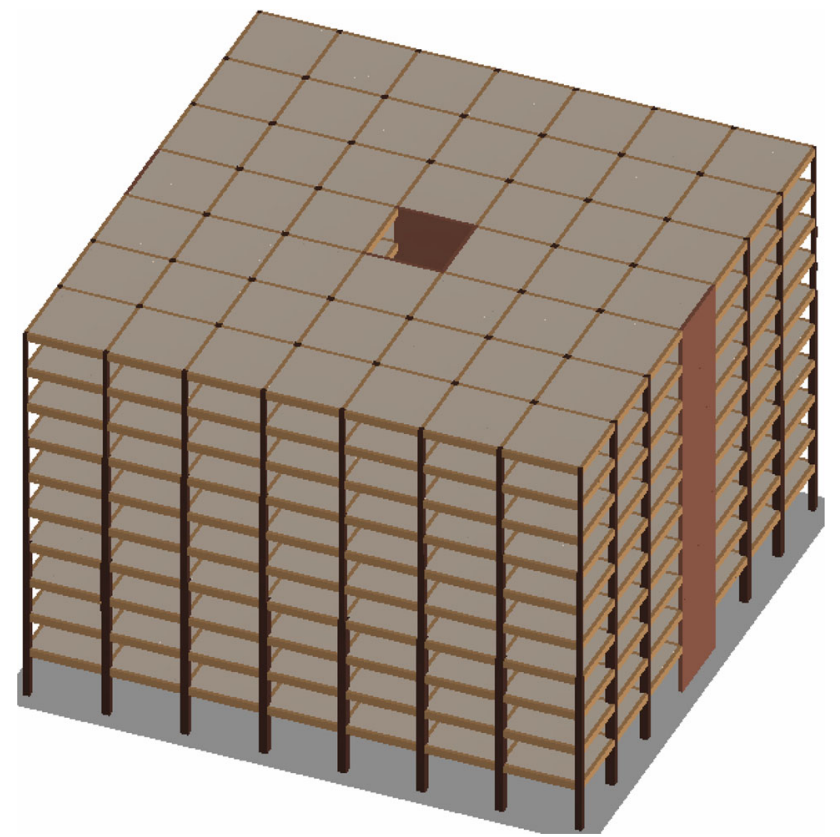

Fig. 8 Isometric view for the ELS model

\section{The effect of lateral load direction}

The effect of lateral load direction was studied in the case of the edge column removal. Three lateral load cases were considered as cases that increase the deflection at the location of the removed column: north to south, east to west and west to east. Three separate analyses were carried out and from analytical results it was concluded that, the effect of lateral load direction is not significant as shown in Fig. 13. Therefore, it was decided that only one lateral load direction was to be considered in each removal case. The direction of this lateral load is the one that causes the largest deflection at the removed support location.

\section{Behavior of three-dimensional bare frames (excluding slabs and walls)}

All of the 3D frame analysis cases showed a partial collapse except for the internal shear wall case. Figure 14 shows the collapse pattern for the collapsed cases. The cause of failure was that, after support removal, the beams behaved differently from what they were designed for. Some beams acted as cantilevers and therefore failed due to insufficient top reinforcement. Others spanned two bays and therefore failed due to insufficient bottom reinforcement. The mode of failure was obviously a flexural one where flexural cracks initiated at the most stressed sections followed by yielding and rupture of longitudinal RFT. Shear was not the predominant factor in the structural behavior, where low values for shear deformations were 
Table 1 Material properties

\begin{tabular}{llllll}
\hline Material & $\begin{array}{l}\text { Young's modulus } \\
(\mathrm{MPa})\end{array}$ & Compressive strength (MPa) & $\begin{array}{l}\text { Tensile strength } \\
(\mathrm{MPa})\end{array}$ & $\begin{array}{l}\text { Yield stress } \\
(\mathrm{MPa})\end{array}$ & $\begin{array}{l}\text { Ultimate strength } \\
(\mathrm{MPa})\end{array}$ \\
\hline Concrete & 22,135 & 25 & 2 & - & - \\
Reinforcement & 200,000 & - & - & 360 & 520 \\
\hline
\end{tabular}

Fig. 9 Removed supports' locations

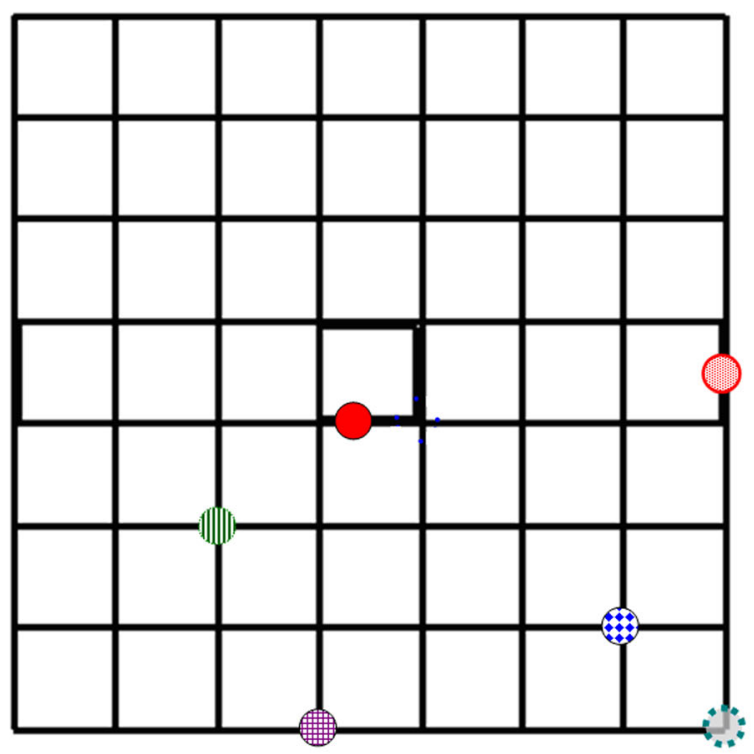

Remove corner column
Remo edge column
Remove internal column-1
Remove internal column-2
Remove Internal shear wall

Remove Internal shear wall generally noticed with low level of stresses in stirrups. The contribution of membrane action of the beams' reinforcement was too small to prevent the structure collapse.

The collapsed areas were the bays directly connected to the removed column. The structure showed a high potential for progressive collapse and therefore it must be redesigned according to UFC guidelines.

In the internal shear wall removal case, the existence of the shear wall in all the upper floors with its huge section helped by safely spanning the three unsupported bays and prevented the structure collapse in the ground, fifth and eighth floors. Additionally, the existence of the remaining parts of the core helped in supporting the structure, in lieu of the removed wall, and prevented the structure collapse as shown in Fig. 15. After the wall removal, its vertical load transferred to the remaining parts of the core and to the adjacent columns. Figure 16 shows two successive views for the axial forces in the columns and walls before and after the wall removal from the ground floor. In such a case, the axial load in the core web increased by $150 \%$ of the gravity loads, while the axial load in the other flange increased by $40 \%$ of the gravity loads. All the axial forces that resulted from the column removal were still less than their ultimate capacities. This is explained by the fact that the columns were designed according to the (ACI 318-08) code which implements higher load factors as compared to UFC guidelines $(1.2 \mathrm{DL}+1.6 \mathrm{LL}$ instead of $1.2 \mathrm{DL}+0.5 \mathrm{LL})$. This helped by increasing margin of safety for the columns. In addition, the strength reduction factors specified by ACI are considered also a margin of safety for column capacities.

In the internal shear wall removal case, the beam maximum rotation was $0.32^{\circ}, 0.14^{\circ}$ and $0.07^{\circ}$ for the ground, fifth and eighth floors, respectively. All these values are less than the UFC limits $\left(3.38^{\circ}\right)$ as shown in Fig. 17. The maximum column rotation was $0.07^{\circ}, 0.07^{\circ}$ and $0.13^{\circ}$ for the ground, fifth and eighth floors, respectively. Similarly, these values are less than the ASCE 41 limits $\left(0.86^{\circ}, 0.85^{\circ}\right.$ and $1.0^{\circ}$, respectively). The joint rotations were $0.37^{\circ}$, $0.13^{\circ}$ and $0.14^{\circ}$ for the ground, fifth and eighth floors, respectively, which are also less than the ASCE 41 limit which is $\left(1.15^{\circ}\right)$.

In the case of the tenth floor, the 3D frame analysis showed partial progressive collapse in the case of internal shear wall removal from the tenth floor. This collapse is explained by the fact that, there are no floors above the tenth floor and hence no Virendeel action could be activated above the removed support. The beams thus spanned two continuous bays and therefore failed due to insufficient bottom reinforcement.

\section{Behavior of coupled frame-wall system}

The 3D frame analysis, without slabs, but including infilled walls in the bays above the removed support was carried 
(a)

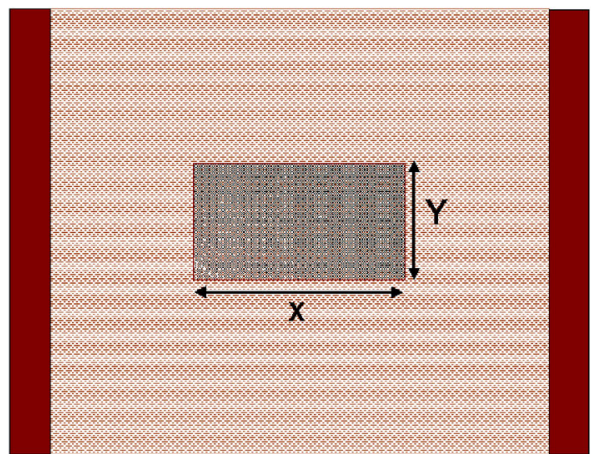

(b)

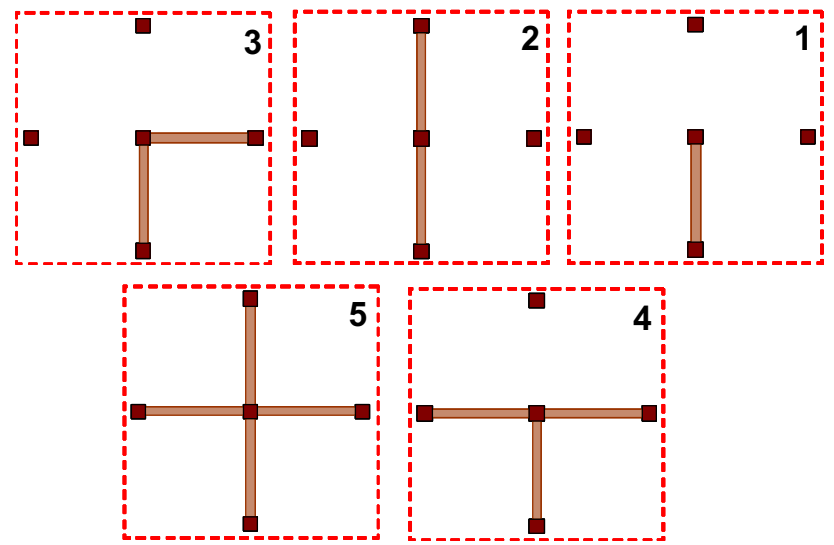

Fig. 10 Nonstructural wall cases. a Edge wall case, b Interior wall case

Table 2 Mesh sensitivity study details

\begin{tabular}{llll}
\hline Analysis & \multicolumn{2}{l}{ Mesh discretization $^{\mathrm{a}}$} \\
\cline { 2 - 4 } & Girder & Column & Slabs \\
\hline 1 & $1 \times 1 \times 8$ & $1 \times 1 \times 10$ & $5 \times 5 \times 2$ \\
2 & $2 \times 2 \times 10$ & $2 \times 2 \times 10$ & $10 \times 10 \times 2$ \\
3 & $3 \times 3 \times 16$ & $3 \times 3 \times 20$ & $14 \times 14 \times 2$ \\
4 & $4 \times 4 \times 20$ & $4 \times 4 \times 25$ & $14 \times 14 \times 2$ \\
\hline
\end{tabular}

${ }^{a}$ Number of elements in cross sections and in the longitudinal direction for beams and column, or number of elements in the slab plan and its depth

out. It was assumed that there are no masonry walls in the ground floor. For the cases of removal of edge supports (corner column, edge column and edge shear wall), a parametric study was carried out to estimate the maximum allowable window opening area and to study the effect of aspect ratio (width to height) which enables the wall to prevent the structure collapse in case of support failure. In case of removal of internal supports, a parametric study was carried out to define the minimum number of interior walls required to prevent the structure's collapse in case of interior column failure.

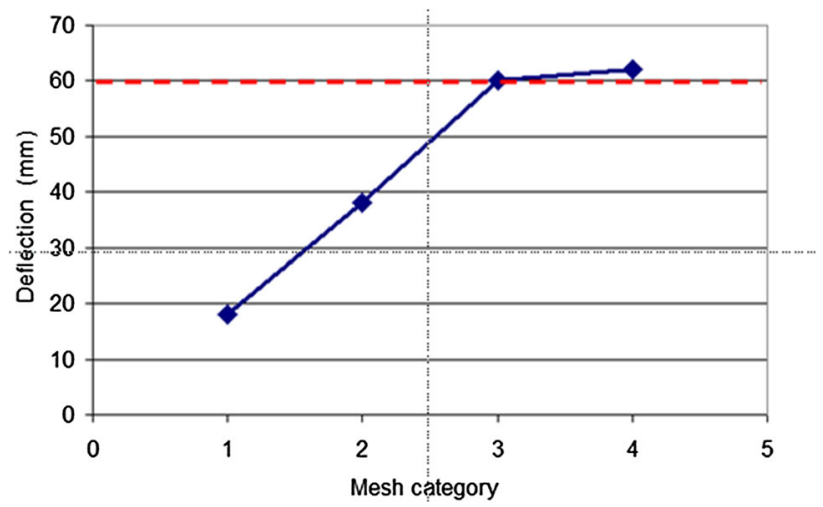

Fig. 11 The relation between the mesh category and the maximum deflection above the removed column

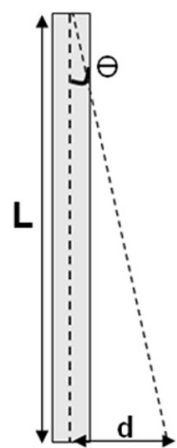

(a) Beam and column rotation

$\Theta=\operatorname{Tan}^{-1}[d /(L)]$

Fig. 12 Beam and column rotation



Fig. 13 Effect of lateral load direction

\section{Corner column removal}

Two aspect ratios were studied (2:1 and 3:1). It was found that the aspect ratio and the window opening area have an effect in preventing the structure's collapse. Using window opening area with area less than or equal to $40 \%$ of the wall area with any aspect ratio will enable the wall to prevent the structure's collapse, while with aspect ratio of 
Fig. 14 Collapse after the supports removal (3D bare frames)

Fig. 15 Structural behavior after removal of internal shear wall (3D bare frames)
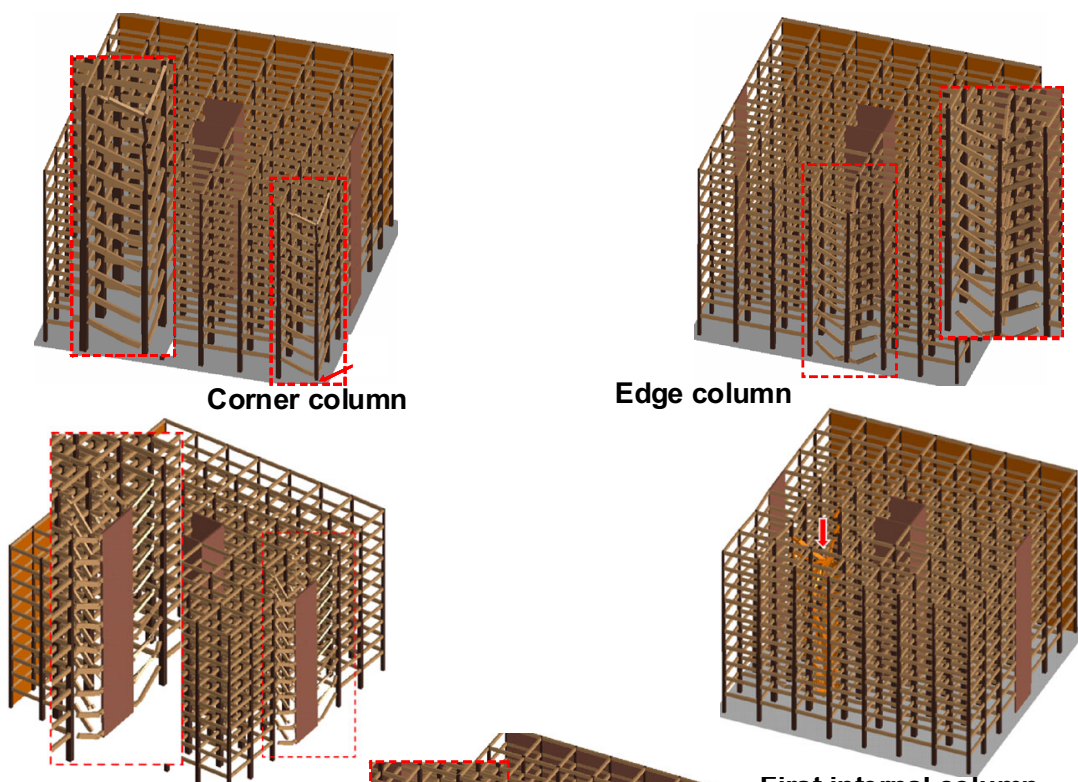

Edge shear wall
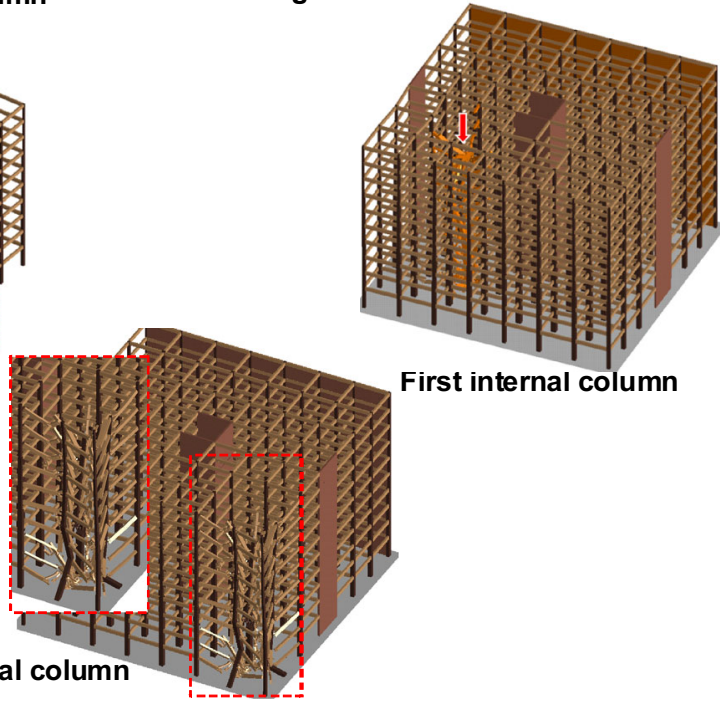

First internal column

Second internal column

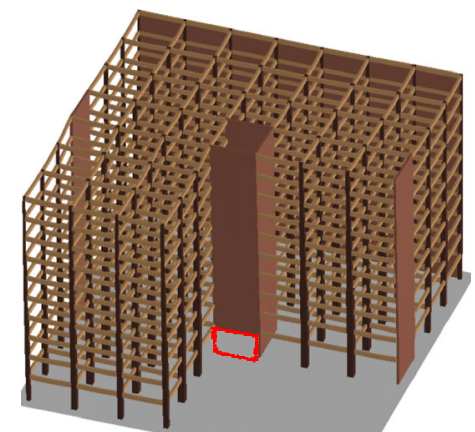

Ground floor

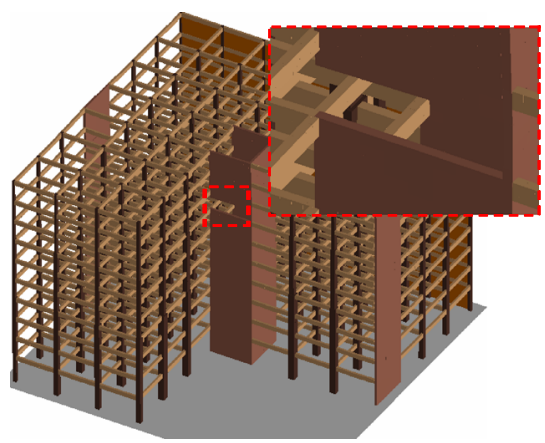

Eighth floor
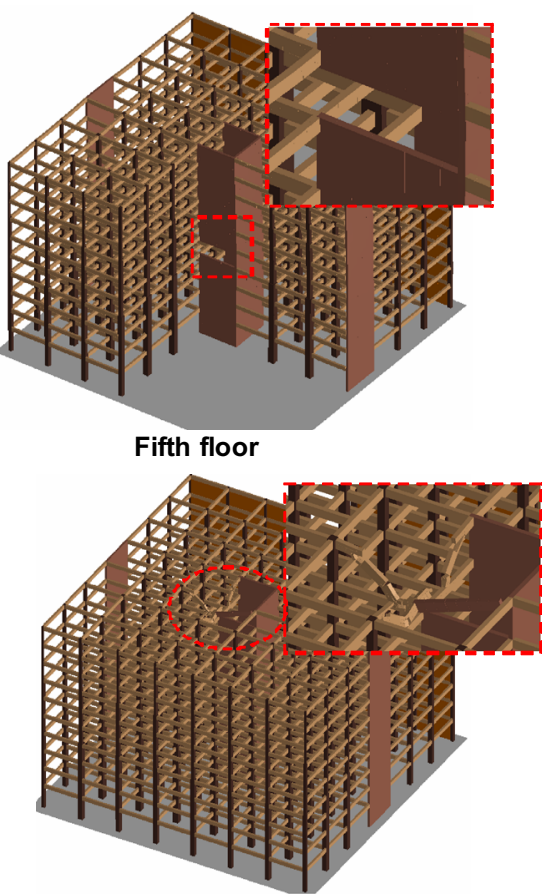

Tenth floor 


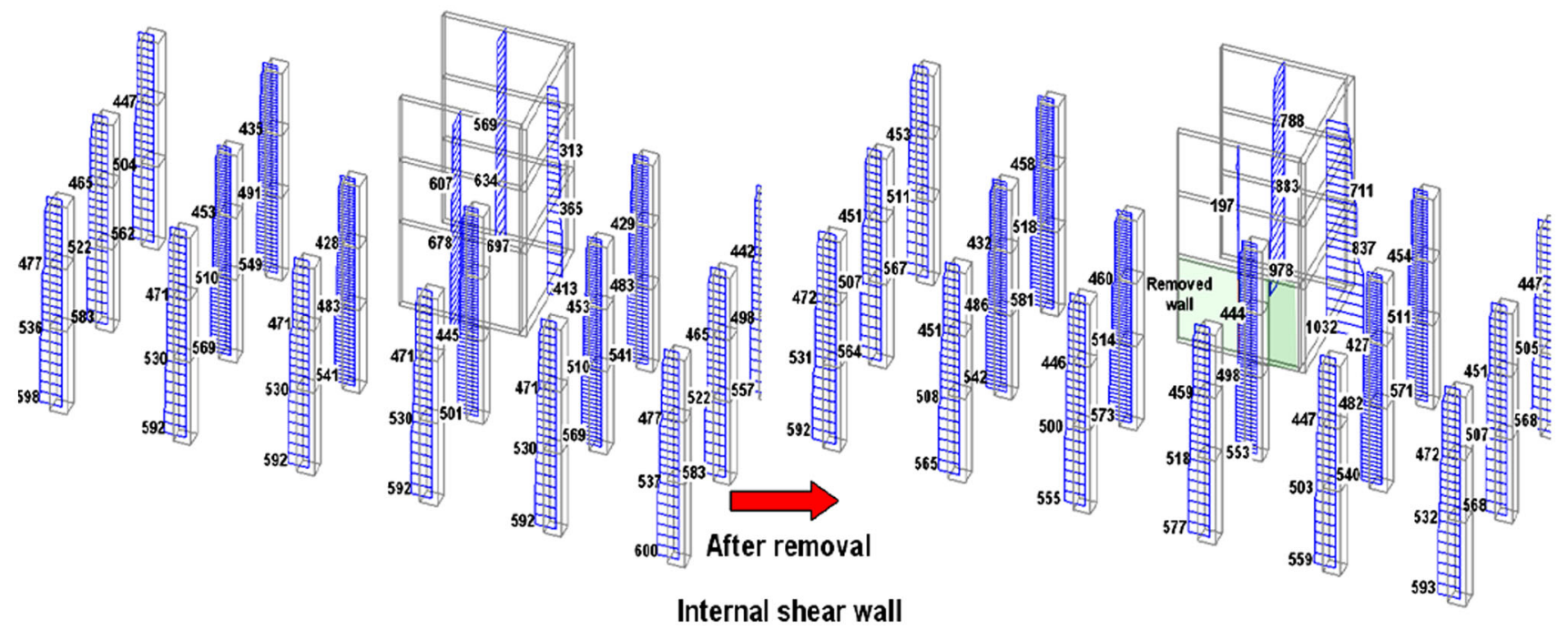

Fig. 16 Axial forces in columns (ton) before and after the internal shear wall removal from the ground floor



Fig. 17 Beam rotation histories in case of removing internal shear wall

(3:1), the window opening area can reach $45 \%$ of the wall area. The collapse prevention was due to the infilled frame behavior. Figure 18 shows the structure's collapse for the aspect ratios (2:1) with window opening area $40 \%$. The maximum beam rotation was $0.2^{\circ}$ and $0.24^{\circ}$ for aspect ratio (2:1) and (3:1), respectively. The two rotation values are less than the UFC rotation limits $\left(3.61^{\circ}\right)$.

\section{Edge column removal}

Using window opening area with area less than or equal to $35 \%$ of the wall area with any aspect ratio will enable the wall to prevent the structure collapse in case of edge column removal. The results show that the window opening aspect ratio has no effect while the area of the opening is the main affecting parameter. The maximum beam rotation was $0.19^{\circ}$ and $0.23^{\circ}$ for aspect ratio (2:1) and (3:1) respectively. The two rotation values are less than the UFC rotation limits $\left(3.61^{\circ}\right)$. Using window opening with aspect ratio (2:1) decreased the beam rotation by $20 \%$ less than that of the aspect ratio $(3: 1)$.

\section{Edge shear wall removal}

The nonstructural masonry walls cannot prevent the structure collapse in the edge shear wall case. The structure collapses even if the wall has no window opening. Figure 19 shows the structure collapse.

Table 3 summarizes the analysis results of the external cases.

\section{First internal column removal}

In the case of the first internal column removal, using one infilled wall above the removed column in nine successive floors or more prevent the structure collapse. The nine floors represent $90 \%$ from the whole number of the structure floors. Figure 20 shows the collapse shape in case of using one wall in eight successive floors only. The maximum beam rotation was $0.45^{\circ}$ which is less than the UFC limits $\left(3.61^{\circ}\right)$.

Using two masonry walls in the same plane above the removed column in five successive floors above the removed column prevent the structure collapse. The five floors represent $50 \%$ of all the floors of the structure. The maximum beam rotation was $0.22^{\circ}$ which is less than the UFC limits $\left(3.61^{\circ}\right)$.

Using two perpendicular masonry walls in four successive floors or more above the removed column prevented the structure collapse. The four floors represent $40 \%$ of all the floors of the structure. The maximum beam rotation was $0.23^{\circ}$ which is less than the UFC limits $\left(3.61^{\circ}\right)$. The 


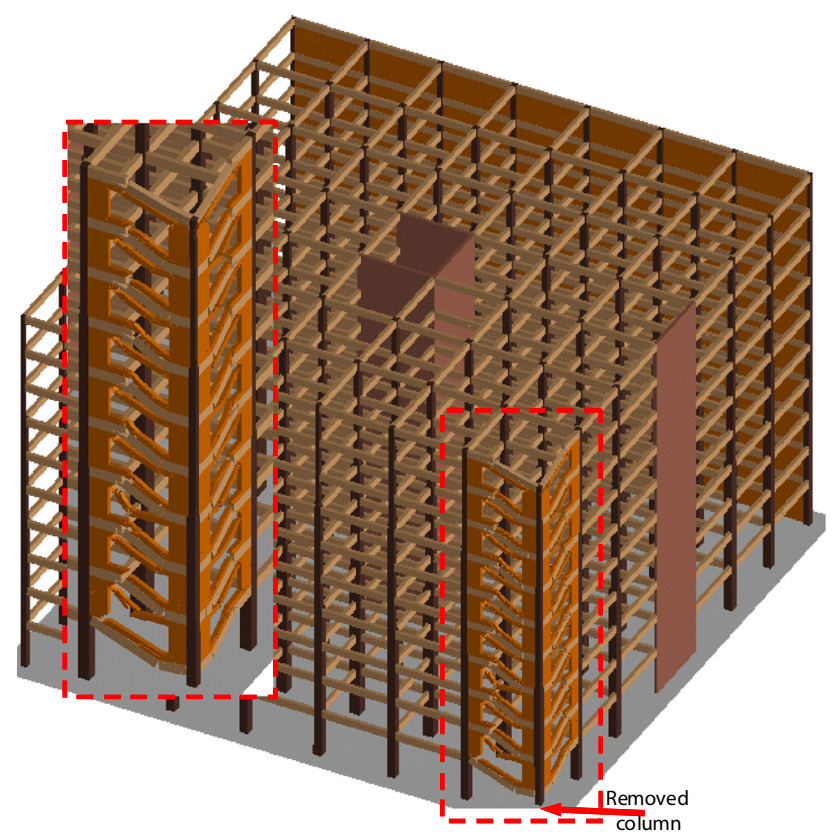

Fig. 18 Collapse shape for window opening with aspect ratio of $(2: 1)$

results show that there is a noticeable difference between using two walls in one plane or perpendicular to each other. The two perpendicular walls are more rigid.

Using three masonry walls above the removed column in four successive floors or more prevented the structure's collapse. The four floors represent $40 \%$ of all the floors of the structure. The maximum beam rotation was $0.13^{\circ}$ which is less than the UFC limits $\left(3.61^{\circ}\right)$ and so the structure is safe.

Using four masonry walls in three successive floors or more above the removed column prevented the structure's collapse. The three floors represent $30 \%$ of all the floors of the structure. The maximum beam rotation was $0.08^{\circ}$ which is less than the UFC limits $\left(3.61^{\circ}\right)$.

\section{Second internal column removal}

Using one wall on the exterior side or on the interior side of the column in all the structure floors above the removed

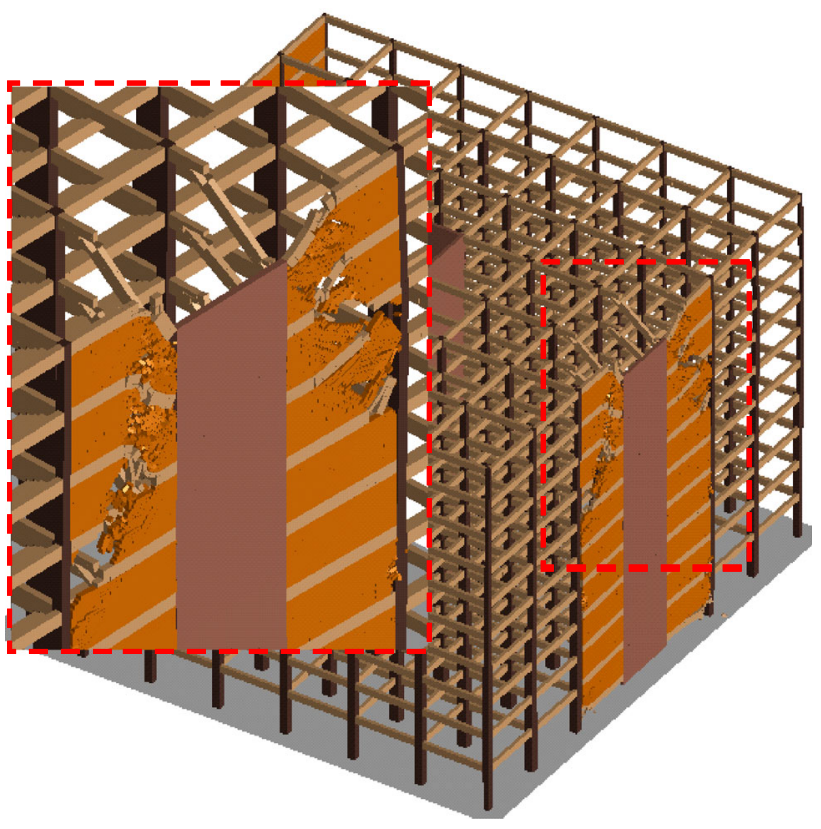

Fig. 19 Structure's collapse in case of using masonry walls in all the floors

column will not prevent the structure collapse. Figure 21 shows the structure's collapse in case of using one wall on the interior side of the removed column in all the structure floors.

Also using two masonry walls in one plane on all the floors above the removed column cannot prevent the structure's collapse.

Using two perpendicular masonry walls on nine successive floors or more above the removed column will prevent the structure's collapse. The nine floors represent $90 \%$ of all the floors of the structure. The maximum beam rotation was $0.39^{\circ}$ which is less than the UFC limits $\left(3.61^{\circ}\right)$. The results show that there is a noticeable difference between using two walls in one plane or perpendicular to each other. The two perpendicular walls are more rigid.

Using three masonry walls on seven successive floors or more above the removed column will prevent the structure collapse. The seven floors represent $70 \%$ of all the floors

Table 3 Summary of the external cases analysis results

\begin{tabular}{|c|c|c|c|c|c|}
\hline Case & $\begin{array}{l}\text { Window } \\
\text { aspect ratio }\end{array}$ & $\begin{array}{l}\text { Maximum window opening area percentage } \\
\text { (window area/wall area) } \%\end{array}$ & $\begin{array}{l}\text { Maximum beam } \\
\text { rotation }\left({ }^{\circ}\right)\end{array}$ & $\begin{array}{l}\text { UFC rotation } \\
\text { limit }\left(^{\circ}\right)\end{array}$ & Effective parameter \\
\hline \multirow{2}{*}{$\begin{array}{l}\text { Corner } \\
\text { Column }\end{array}$} & $2: 1$ & 40 & 0.20 & 3.61 & \multirow{2}{*}{$\begin{array}{l}\text { Aspect ratio and the } \\
\text { window opening area }\end{array}$} \\
\hline & $3: 1$ & 45 & 0.32 & 3.61 & \\
\hline \multirow{2}{*}{$\begin{array}{l}\text { Edge } \\
\text { Column }\end{array}$} & $2: 1$ & 35 & 0.19 & 3.61 & \multirow[t]{2}{*}{ Window opening area } \\
\hline & $3: 1$ & 35 & 0.23 & 3.61 & \\
\hline $\begin{array}{l}\text { Edge } \\
\text { shear } \\
\text { wall }\end{array}$ & Collapse & & & & \\
\hline
\end{tabular}




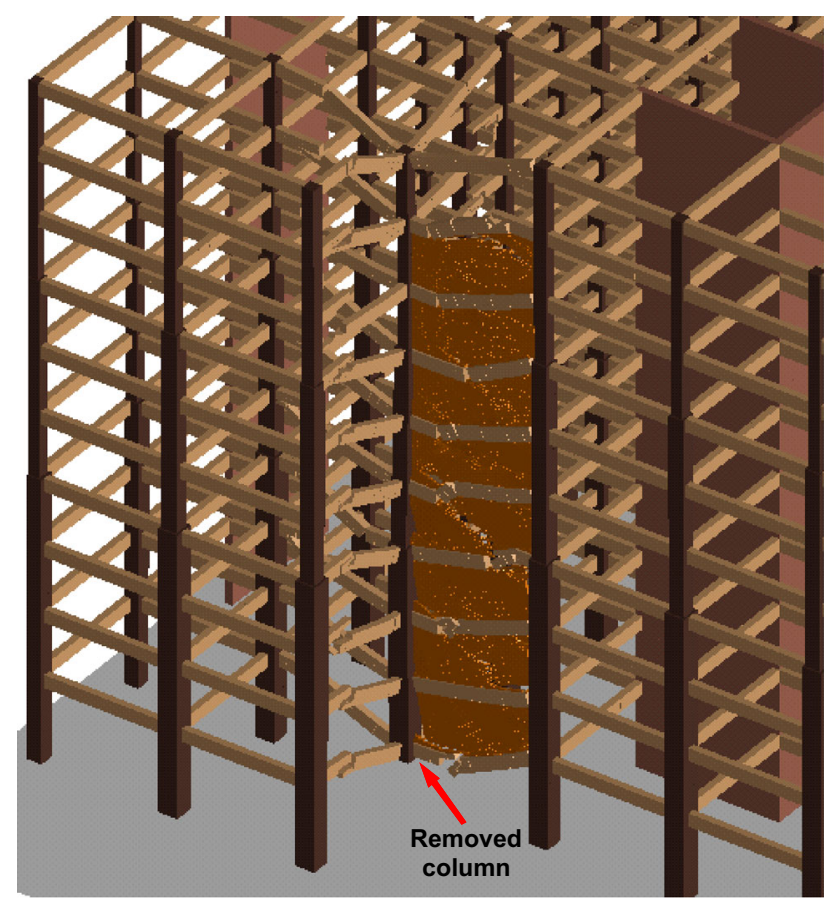

Fig. 20 Structure's collapse in case of using one masonry wall on eight successive floors

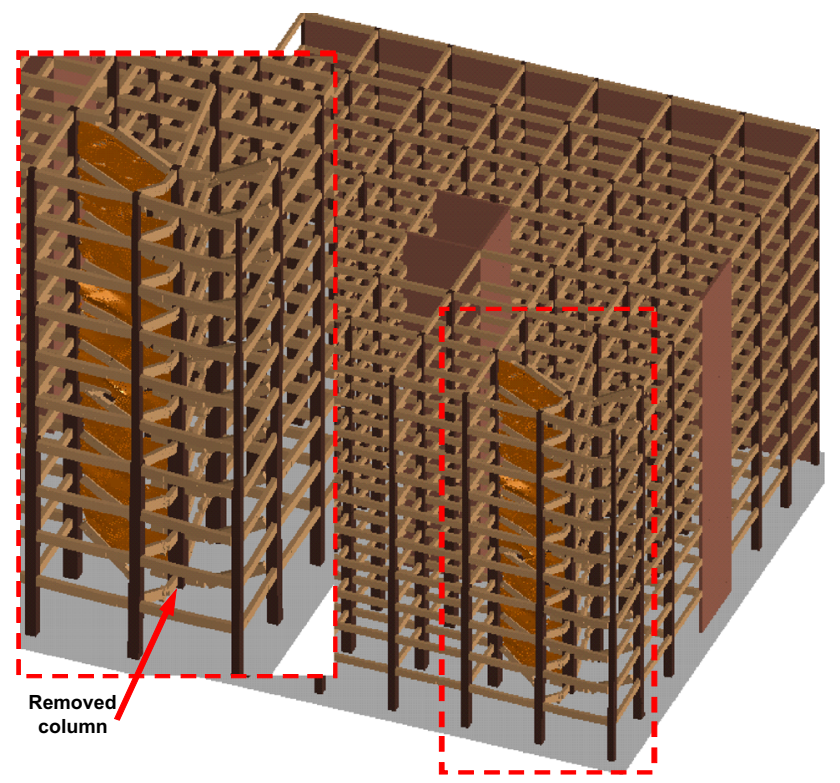

Fig. 21 Structure's collapse in case of one wall on the internal side

of the structure. The maximum beam rotation was $0.44^{\circ}$ which is less than the UFC limits $\left(3.61^{\circ}\right)$.

Using four masonry walls in five successive floors or more above the removed column will prevent the structure's collapse. The five floors represent $50 \%$ of all the floors of the structure. The maximum beam rotation was $0.09^{\circ}$ which is less than the UFC limits $\left(3.61^{\circ}\right)$. Table 4 summarizes the analysis results of the inertial cases.
Table 4 Summary of the internal cases analysis results

\begin{tabular}{|c|c|c|c|c|}
\hline Case & Wall orientation & $\begin{array}{l}\text { Required } \\
\text { number of } \\
\text { floors }\end{array}$ & $\begin{array}{l}\text { Maximum } \\
\text { beam } \\
\text { rotation }\left(^{\circ}\right)\end{array}$ & $\begin{array}{l}\mathrm{UFC} \\
\text { rotation } \\
\operatorname{limit}\left(^{\circ}\right)\end{array}$ \\
\hline \multirow{5}{*}{$\begin{array}{l}\text { First } \\
\text { internal } \\
\text { column }\end{array}$} & One wall & 9 & 0.45 & 3.61 \\
\hline & $\begin{array}{l}\text { Two walls in } \\
\text { the same } \\
\text { plane }\end{array}$ & 4 & 0.23 & 3.61 \\
\hline & $\begin{array}{l}\text { Two } \\
\text { perpendicular } \\
\text { walls }\end{array}$ & 5 & 0.22 & 3.61 \\
\hline & Three walls & 4 & 0.13 & 3.61 \\
\hline & Four walls & 3 & 0.08 & 3.61 \\
\hline \multirow{5}{*}{$\begin{array}{l}\text { Second } \\
\text { internal } \\
\text { column }\end{array}$} & One wall & Collapse & & \\
\hline & $\begin{array}{l}\text { Two walls in } \\
\text { the same } \\
\text { plane }\end{array}$ & Collapse & & \\
\hline & $\begin{array}{l}\text { Two } \\
\text { perpendicular } \\
\text { walls }\end{array}$ & 9 & 0.39 & 3.61 \\
\hline & Three walls & 7 & 0.44 & 3.61 \\
\hline & Four walls & 5 & 0.09 & 3.61 \\
\hline
\end{tabular}

\section{Conclusion}

The AEM was used to evaluate the resistance of typical multi-story reinforced concrete structures designed according to ACI 318-08 code and ASCE 7-10 and subjected to accidental loss of vertical support according to GSA guidelines. Based on the analytical results, the following conclusions were obtained:

1. Neglecting nonstructural masonry walls in progressive collapse analysis may lead to incorrect structural behavior and uneconomic design. The infilled frame action showed a significant role in collapse resistance.

2. For 3D bare frame analysis excluding infilled walls, the cases of loss of corner column, edge column, edge shear wall and internal columns showed partial collapse. This is attributed to the fact that, after support removal, the beams behaved differently from what they were designed for. Some beams acted as cantilevers and therefore failed due to insufficient top reinforcement. Others spanned two bays and therefore failed due to insufficient bottom reinforcement.

3. For 3D bare frame analysis excluding infilled walls, the case of loss of the internal shear wall did not show any collapse except in the tenth floor case. This is explained by the existence of the shear wall in all the upper floors with its huge section helping by safely spanning the three unsupported bays and prevented the structure. Additionally, the existence of the remaining parts of the core helped in supporting the structure. 
4. The collapse can be prevented by "meeting the UFC limits" in case of internal column failure if any of the following conditions are satisfied:

- Four perpendicular walls above bays surrounding the lost column in successive floors representing at least $50 \%$ of all the floors of the structure.

- Three perpendicular walls above bays surrounding the lost column in successive floors representing at least $70 \%$ of all the floors of the structure.

- Two perpendicular walls above bays surrounding the lost column in successive floors representing at least $90 \%$ of all the floors of the structure.

5. The collapse cannot be prevented in case of first row of internal column by using two walls in the same plane in all the floor above the failed column. The collapse can be prevented in case of the failure of all the other internal column by using one wall in all the floors or two walls in the same plane in five successive floors above it.

6. The masonry walls cannot prevent the structure's collapse in case the edge shear wall collapses.

7. The area of the window opening has a significant effect on the wall's ability to resist the structure's collapse, while the aspect ratio does not.

8. Using window opening area less than 40 and $35 \%$, of the wall area above the bays surrounding the removed column for corner column and edge column, respectively, enables the wall to prevent the structure's collapse and the structure then meets the UFC limits.

Open Access This article is distributed under the terms of the Creative Commons Attribution 4.0 International License (http://creativecommons.org/licenses/by/4.0/), which permits unrestricted use, distribution, and reproduction in any medium, provided you give appropriate credit to the original author(s) and the source, provide a link to the Creative Commons license, and indicate if changes were made.

\section{References}

ACI 318-08 (2008) Building code requirements for structural concrete and commentary. American Concrete Institute, MI

ASCE/SEI 7-05 (2005) Minimum design loads for buildings and other structures. American Society of Civil Engineers, NY

ASCE/SEI 41/06 (2006) Seismic rehabilitation of existing buildings, American Society of Civil Engineers, NY

Applied Science International (2004-2015) LLC. http://www.apllieds cienceint.com

Bathe K (1982) Solution of equilibrium equations in dynamic analysis. Prentice Hall, Englewoods Cliffs

Chopra A (1995) Dynamics of structures: theory and applications to earthquake engineering. Prentice Hall, Englewoods Cliffs
Department Of Defense. DoD (2009) Design of buildings to resist progressive collapse, unified facilities criteria (UFC, 4-023-03). U.S. Department of Defense, USA

Galal K, El-Sawy T (2010) Effect of retrofit strategies on mitigating progressive collapse of steel frame structures. J Constr Steel Res 66(4):520-531

General Service Administration (GSA) (2003) Progressive collapse analysis and design guidelines for new federal office buildings and major modernization projects. USA

Hao H, Ma GW, Lu Y (2002) Damage assessment of masonry infilled $\mathrm{RC}$ frames subjected to blasting induced ground excitations. Eng Struct 24(6):799-809

Helmy H, Salem H, Tageldin H (2009) Numerical simulation of Charlotte Coliseum demolition using the applied element method. USNCCM-10 conference-Ohio-USA; 2009

Helmy H, Salem H, Mourad S (2012) Progressive Collapse Assessment of Framed Reinforced Concrete Structures According to UFC Guidelines for Alternative Path Method. Eng Struct 42:127-141

Maekawa K, Okamura H (1983) The deformational behavior and constitutive equation of concrete using the elsto-plastic and fracture model. J Fac Eng Univ Tokyo (B) 37(2);253-328

Meguro K, Tagel-Din H (2000) Applied element method for structural analysis: theory and application for linear materials. Struct Eng Earthq Eng Int J Jpn Soc Civ Eng (JSCE) 17(1);21s-35s

Meguro K, Tagel-Din H (2001) Applied element simulation of RC structures under cyclic loading. ASCE 127(11):1295-1305

Park H, Suk C, Kim S (2009) Collapse modeling of model RC structures using the applied element method. J Korean Soc Roc Mech Tunn Undergr Space 19(1);43-51

Razzaghi MS, Javidnia M (2015) Evaluation of the effect of infill walls on seismic performance of RC dual frames. Int $\mathbf{J}$ Adv Struct Eng (IJASE) 7(1):49-54

Ristic D, Yamada Y, Iemura H (1986) Stress-strain based modeling of hysteretic structures under earthquake induced bending and varying axial loads. Research report No. 86-ST-01, School of Civil Engineering, Kyoto University, Kyoto, Japan; 1986

Salem H (2011) Computer-aided design of framed reinforced concrete structures subjected to flood scouring. J Am Sci 7(10):191-200

Salem H, El-Fouly A, Tagel-Din H (2011) Toward an economic design of reinforced concrete structures against progressive collapse. Eng Struct 33:3341-3350

Sasani M (2008) Response of a reinforced concrete infilled-frame structure to removal of two adjacent columns. Eng Struct 30:2478-2491

Sasani M, Sagiroglu S (2008) Progressive collapse resistance of hotel San Diego. J Struct Eng 134(3):478-488

Shankar N (2004) Progressive collapse basics. In: NASCC Proceedings

Tagel-Din H, Meguro K (2000a) Applied element method for simulation of nonlinear materials: theory and application for RC structures. Struct Eng Earthq Eng Int J Jpn Soc Civ Eng (JSCE) 17(2);123s-148s

Tagel-Din H, Meguro K (2000b) Applied element method for dynamic large deformations analysis of structures. Struct Eng Earthq Eng Int J Jpn Soc Civ Eng (JSCE) 17(2);215s-224s

Tagel-Din H, Rahman N (2004) Extreme loading: breaks through finite element barriers. Struct Eng 5(6):32-40

Tsai MH, Huang TC (2013) Progressive collapse analysis of an RC building with exterior partially infilled walls. Struct Des Tall Spec Build 22(4):327-348

Wibowo H, Reshotkina S, Lau D (2009) Modelling progressive collapse of RC bridges during earthquakes, CSCE Annual General Conference; 2009; GC-176-1-11 